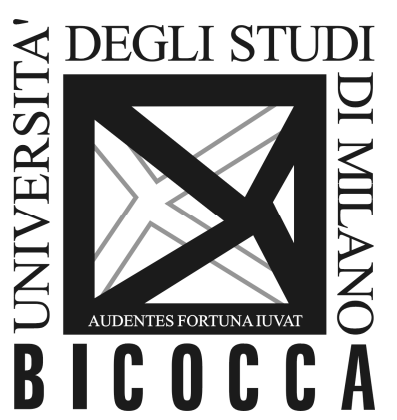

\author{
DEPARTMENT OF ECONOMICS, \\ MANAGEMENT AND STATISTICS \\ UNIVERSITY OF MILAN - BICOCCA
}

DEMS WORKING PAPER SERIES

Risk Premiums, Nominal Rigidities and Limited Asset Market Participation

Lorenzo Menna, Patrizio Tirelli

No. 388 - October 2018

Dipartimento di Economia, Metodi Quantitativi e Strategie di Impresa Università degli Studi di Milano - Bicocca

http://dems.unimib.it/ 


\title{
Risk Premiums, Nominal Rigidities and Limited Asset Market Participation.
}

\author{
Lorenzo Menna* Patrizio Tirelli ${ }^{\dagger}$
}

October 24, 2018

\begin{abstract}
Recent developments in the asset pricing literature show that a combination of technology and distributive shocks can rationalize observed risk premia when firm ownership is concentrated in the hands of few households. We find that distributive shocks are unnecessary when nominal price rigidity is taken into account. Our results are driven by the income redistribution associated to procyclical variations in profit margins when firms ownership is concentrated, prices are sticky and technology shocks hit the economy. In this regard, standard DSGE models that allow for firm ownership concentration have the potential to replicate both business cycle facts and the moments of financial variables.
\end{abstract}

Jel codes: E32 G12

Keywords: asset pricing, equity premium, limited asset market participation, business cycle, DSGE, sticky prices.

*Banco de Mexico. Direccion General de Estabilidad Financiera, Direccion de Analisis de Riesgos Macrofinancieros, Banco de Mexico, Av. 5 de Mayo 1-1er Piso Col. Centro, Mexico City, 06059, Mexico. The opinions expressed here are those of the author and do not necessarily represent Banco de Mexico's or its board of governors' opinions. Corresponding author: emails: lorenzo.menna@banxico.org.mx and lorenzomenna@yahoo.it.

${ }^{\dagger}$ Prof. Patrizio Tirelli, University of Milano-Bicocca, Piazza dell'Ateneo Nuovo, 120100 Milano, Italy. Email: patrizio.tirelli@unimib.it 


\section{Introduction}

The standard neoclassical finance model based on the representative agent (RA henceforth) assumption predicts that assets are priced according to their correlation with aggregate consumption growth, but this latter variable is apparently too smooth for the model to replicate the empirically observed equity premium (Mehra and Prescott, 1985). In response to this, and to other related "puzzles", the productionbased asset pricing literature has explored the connection between the stylized facts of the business cycle and the empirical regularities that characterize the financial markets, such as the equity premium, its Sharpe ratio, the risk-free rate and return autocorrelations. Lettau (2003), Jermann (1998), Boldrin, Christiano and Fischer (2001) and Uhlig (2007), have shown that the predicted unconditional risk premium increases if one extends the real business cycle model to account for real frictions. Nevertheless, these models still find it difficult to replicate the relatively large risk premia observed in the data.

Several contributions have considered real business cycle models where only a subset of households participate in the stock exchange market. In this framework the concentration of capital ownership raises the correlation between stockholders' consumption growth and stock returns. This is consistent with empirical evidence suggesting that the consumption of stockholders is more volatile than that of nonstockholders and is more strongly correlated with the excess return on the stock market (Mankiw and Zeldes, 1991). Polkovnichenko (2004) shows that restricting asset market participation cannot warrant a sufficiently large increase in the theoretical risk premium. In a similar framework, Guvenen (2009) assumes that stock holders are characterized by a relatively large elasticity of intertemporal substitution in consumption. In addition, he posits that shareholders provide partial income insurance to bond holders. His model can replicate the empirical facts concerning financial variables but predicts excessive volatility in consumption growth and in the labor supply.

Other contributions assume Limited Asset Market Participation (LAMP henceforth), as in Weil (1992). The LAMP hypothesis implies that only a fraction of consumers participate in financial markets whereas the rest of the population, i.e. the rule-of-thumb or hand-to-mouth consumers (RT consumers, henceforth), do not accumulate any wealth and entirely consume their current income. In these models distributive shocks are necesssary to cause a strong covariance between asset holders consumption and asset returns. The key message of this strand of literature is that asset return patterns might be explained by shocks that require transfers to workers at times when shareholders cash flow is relatively low. In Danthine et al. (2008) 
and De Graeve et al. (2010) long-term labour contracts ensure risk sharing between relatively more risk averse workers, whose weight is conventionally set, respectively, at $50 \%$ and $60 \%$ of the population ${ }^{1}$ and firms. The negative correlation between a workers' bargaining power shock and the productivity shock is then necessary to obtain the covariance between stockholders consumption growth and equity returns which allows to replicate risk premiums. In Lansing (2014) the labor market is perfectly competitive and the distributive shock, modelled as a disturbance to the capital income share, allows to replicate $60 \%$ of the empirically observed risk premium under the assumption that only $10 \%$ of the population participate in financial markets.

Asset pricing models have therefore evolved from the original structure, essentially $\mathrm{RBC}$, to incorporate agents heterogeneity and in some cases wage rigidity, but they typically neglect one key develpment in the DSGE literature, i.e. goods price rigidity. In this regard the only notable exception is De Paoli et al. (2010), who confine their analysis to the representative agent assumption and find that sticky prices increase the unconditional premium in case of aggregate demand shocks and decrease it in case of aggregate supply shocks.

Our analysis starts from the consideration that the LAMP hypothesis has important effects in DSGE models that account for price rigidity. Several contributions have pointed out that the combination of LAMP and price stickiness may cause model indeterminacy (Galì et al., 2004, Bilbiie 2008, Motta and Tirelli, 2013a) and may also explain certain business cycle facts such as the effects of government spending on consumption (Galì et al., 2007), negative co-movements between productivity and hours (Furlanetto and Seneca, 2012), redistributive effects of monetary policy shocks (Motta and Tirelli, 2013b). In all these cases results are driven by the income redistibution associated to variations in profit margins when firms ownership is concentrated and prices are sticky. The same mechanism should naturally emerge as a key driver in determining a strong correlation between stockholders consumption and equity returns if technology shocks cause a procyclical increase in profit margins when prices are sticky.

We therefore introduce LAMP in an otherwise standard DSGE model, akin to Smets and Wouters (2007) and De Paoli et al (2010). In a nutshell, the key message of the paper is that DSGE models characterized by the LAMP hypothesis can replicate the moments of financial variables without imposing redistributive shocks. In fact sticky prices cause a redistribution of factor incomes whenever shocks hit the

\footnotetext{
${ }^{1}$ De Graeve et al (2010) also allow for a third agent, a bondholder, who invests in bonds and not in stocks. This approach can be seen as a combination of the framework of Danthine et al (2008) and that of Guvenen (2009).
} 
economy. For instance a positive productivity shock raises firms profit margins and reduces the labor share, in analogy with the findings in Smets and Wouters (2007) and in references cited therein. If wealth is concentrated in the hands of relatively few investors, i. e. the proportion of RT consumers is sufficiently large, the resulting strong correlation between stockholders consumption and profits implies an empirically plausible risk premium. In addition, the large effect of dividends volatility on the standard deviation of Ricardian households' consumption unambiguously increases the precautionary savings and reduces the riskless rate. Thus LAMP greatly improves model fit of both the equity premium and the riskless rate. Our model also produces a term premium close to that found in the data and exhibits substantial time variation and countercyclicality of the risk premia.

The remainder of the paper is organized as follows. Section 2 presents and derives the model. Section 3 presents the impulse responses and the simulation results. Section 5 draws the conclusions and the perspectives for future research.

\section{The Model}

We assume a continuum of households indexed by $i, i \in[0,1]$. The key distinction between asset holders and RT consumers concerns intertemporal optimization of consumption decisions. Asset holders take into account future utility when choosing consumption and portfolio composition. RT consumers spend their whole income every period, thus they do not hold any wealth. RT consumers (rt) and assetholders or Ricardian consumers $(o)$ are defined over the intervals $[0, \psi]$ and $(\psi, 1]$ respectively. All households share the same utility function:

$$
U\left(c_{t}^{i}, n_{t}^{i}\right)=\frac{1}{1-\sigma}\left(\frac{c_{t}^{i}}{c_{t}^{H}}\right)^{1-\sigma}-\theta \frac{1}{1+\gamma} n_{t}^{i(1+\gamma)}
$$

where $n_{t}^{i}=\left[\int_{0}^{1}\left(n_{h, t}^{i}\right)^{\frac{\nu-1}{\nu}} d h\right]^{\frac{\nu}{\nu-1}}$ defines the labor bundle, $c_{t}^{i}$ is the consumption good 2 and $c_{t}^{H}=c_{t-1}^{\chi}$ denotes external consumption habits.

Campbell and Cochrane (1999) popularized in finance models the use of preferences based on external-habits-in-differences specifications, $U\left(c_{t}^{i}\right)=$ $\left.\frac{1}{1-\sigma}\left(c_{t}^{i}-c_{t}^{H}\right)^{1-\sigma}\right]_{3}^{3}$ Carroll (2000) criticized this choice because habits in difference

\footnotetext{
${ }^{2}$ The consumption good is produced by final good firms that aggregate the differentiated goods produced by intermediate firms. This approach is equivalent to assuming that households obtain utility from a consumption bundle composed of differentiated goods.

${ }^{3}$ The consumption habits specification chosen has little importance in DSGE models that are based on the representative agent hypothesis and focus on first-order approximations (Dennis, 2009).
} 
can generate a negative marginal utility of consumption unless some ad hoc constraint is imposed onto the habit functional. The problem is certainly relevant in our context where consumption of RT households may be substantially lower than average. Moreover, we found that the combination of LAMP and external-habits-indifferences may cause indeterminacy even for a relatively small share of RT consumers (as in Motta and Tirelli, 2013a). For these reasons we consider the habit-in-ratio specification used in Abel (1988) asset pricing model and in Leeper et al (2009) business cycle model.

In asset pricing models based on the RA assumption, habits-in-difference have been preferred to the habits-in-ratio specification because the latter is apparently unable to affect the cyclical properties of the risk premium. Right from the outset, it should be noted that under LAMP this undesirable implication of the habit-in-ratio assumption simply vanishes (see our discussion in section 3 below).

\subsection{Ricardian households}

The representative Ricardian household has access to financial markets and maximizes her lifetime discounted utility subject to the budget constraint

$$
\begin{aligned}
& P_{t} c_{t}^{o}+V_{t}^{N} B_{t}^{N, o}+v_{t}^{R} P_{t} B_{t}^{R, o}+V_{t}^{e q} S_{t}^{o}+\left(v_{t}^{L}-1\right) P_{t} B^{L, o} \leq \\
& W_{t} n_{t}^{o}+B_{t-1}^{N, o}+B_{t-1}^{R, o} P_{t}+\left(V_{t}^{e q}+D_{t}\right) S_{t-1}^{o}+\delta^{B} v_{t}^{L} B_{t-1}^{L, o} P_{t}
\end{aligned}
$$

$B^{N, o}, B^{R, o}$ and $S^{o}$ are respectively the number of nominal one period bonds, indexed one period bonds and firm shares traded by the household. $V^{N}, V^{e q}$ and $P$, respectively define the dollar prices of nominal bonds, of the equity index and of the consumption good; whilst $v_{t}^{R}$ define the real price of the indexed bond. $W$ defines the nominal wage, $D$ is the nominal dividend payment received from owned firms.

Following Rudebusch and Swanson (2012), we introduce a geometrically depreciating consol, $B^{L, o}$, to conveniently compute long term interest rates and obtain the model implied term premium. Adjusting parameter $\delta^{B}$, the consol can be given any duration. $v^{L}$ is the real price of the consol 4 The household chooses consumption, nominal bonds, indexed bonds, consols and equity holdings while delegating the wage choice to a union. As in De Paoli et al (2010), Ricardian households do not invest directly in capital. Investment in capital is carried out at the level of the

\footnotetext{
${ }^{4}$ We consider an indexed consol to avoid dealing with the effects of expected inflation and inflation risk on the term premium. Our model abstracts from trend inflation and our analysis concentrates only on the effects of a productivity shock. A richer model is needed if one wants to replicate the time series behaviour of inflation.
} 
intermediate firms. Hence dividends contain both extra-profits deriving from monopolistic competition and the normal return on capital. The first order conditions of the problem are:

$$
\begin{gathered}
\lambda_{t}^{o}=\left(c_{t}^{o}\right)^{-\sigma}\left(\frac{1}{c_{t-1}^{\chi}}\right)^{1-\sigma} \\
V_{t}^{e q}=\beta E_{t}\left(\frac{\lambda_{t+1}^{o}}{\lambda_{t}^{o}} \frac{V_{t+1}^{e q}+D_{t+1}}{\pi_{t+1}}\right) \\
v_{t}^{R}=\beta E_{t}\left(\frac{\lambda_{t+1}^{o}}{\lambda_{t}^{o}}\right) \\
V_{t}^{N}=\frac{1}{R_{t, t+1}^{N}}=\beta E_{t}\left(\frac{\lambda_{t+1}^{o}}{\lambda_{t}^{o}} \frac{1}{\pi_{t+1}}\right) \\
v_{t}^{L}=1+\delta^{B} \beta E_{t}\left(\frac{\lambda_{t+1}^{o}}{\lambda_{t}^{o}} v_{t+1}^{L}\right) \\
c_{t}^{o}=w_{t} n_{t}+\frac{d_{t}}{1-\psi}
\end{gathered}
$$

where $\pi_{t}=\frac{P_{t}}{P_{t-1}}$ defines the inflation rate, $R^{N}$ the nominal interest rate and $\lambda_{t}^{o}$ is the marginal utility of consumption. The market clearing conditions for the equity and bonds markets are: $S_{t}^{o}(1-\psi)=1, B_{t}^{N, o}=B_{t}^{R, o}=B_{t}^{L, o}=0$.

\subsection{RT Households}

RT households do not optimize and simply consume their labor income each period. Their budget constraint is $P_{t} c_{t}^{r t}=W_{t} n_{t}$. The marginal utility of consumption for RT households is:

$$
\lambda_{t}^{r t}=\left(c_{t}^{r t}\right)^{-\sigma}\left(\frac{1}{c_{t-1}^{\chi}}\right)^{1-\sigma}
$$

\subsection{Aggregation among households}

Average marginal utility and aggregate consumption respectively are

$$
\begin{aligned}
\lambda_{t} & =\psi \lambda_{t}^{o}+(1-\psi) \lambda_{t}^{r t} \\
c_{t} & =(1-\psi) c_{t}^{o}+\psi c_{t}^{r t}
\end{aligned}
$$




\subsection{Unions}

There is one labour union for each differentiated labor type. The representative labour union solves the following problem:

$$
\begin{gathered}
\max E_{0} \Sigma_{t=0}^{\infty} \beta^{t}\left[(1-\psi) U\left(c_{t}^{o}, n_{t}\left(W_{h, t}\right)\right)+\psi U\left(c_{t}^{r t}, n_{t}\left(W_{h, t}\right)\right)\right] \\
\text { s.t. } \quad P_{t} c_{t}^{o}=\int_{0}^{1} W_{h, t}\left(\frac{W_{h, t}}{W_{t}}\right)^{-\nu} d h n_{t}^{d}+\frac{D_{t}}{1-\psi}-\frac{X}{2}\left(\frac{W_{h, t}}{W_{h, t-1}}-1\right)^{2} P_{t} n_{t}^{d} \\
P_{t} c_{t}^{r t}=\int_{0}^{1} W_{h, t}\left(\frac{W_{h, t}}{W_{t}}\right)^{-\nu} d h n_{t}^{d}-\frac{X}{2}\left(\frac{W_{h, t}}{W_{h, t-1}}-1\right)^{2} P_{t} n_{t}^{d}
\end{gathered}
$$

The first order condition is

$$
\begin{gathered}
-\frac{\psi U_{n}\left(c_{t}^{o}, n_{t}\right)+(1-\psi) U_{n}\left(c_{t}^{r t}, n_{t}\right)}{\lambda_{t}}=\frac{\nu-1}{\nu} w_{t}+\frac{X}{\nu}\left(\pi_{W, t} \pi_{t}-1\right) \pi_{W, t} \pi_{t} \\
-\beta E_{t}\left[\frac{\lambda_{t+1}}{\lambda_{t}} \frac{X}{\nu}\left(\pi_{W, t+1} \pi_{t+1}-1\right) \pi_{W, t+1} \pi_{t+1} \frac{n_{t+1}}{n_{t}}\right]
\end{gathered}
$$

where

$$
U_{n}\left(c_{t}^{i}, n_{t}\right)=\theta n_{t}^{\gamma}: i=o, r t
$$

and $\pi_{W, t}$ is real wage inflation, that is $\frac{W_{t}}{W_{t-1}} \frac{1}{\pi_{t}}$. Notice that differently from the Calvo setting there is no wage dispersion in equilibrium, hence $n_{t}=n_{t}^{d}$.

\subsection{Labour packers}

Labour packers buy the differentiated labour types from unions and sell the aggregated labour bundle to intermediate goods firms. They maximize profits under a Dixit-Stiglitz production function and operate under perfect competition:

\footnotetext{
${ }^{5}$ We assume that the nominal wage adjustment cost is intangible. In section 2.6 we make the same assumption for the price adjustment cost, following De Paoli et al (2010). In a separate exercise, we solved the model with tangible nominal adjustment costs and found that our results are unaffected. The assumption that wage adjustment costs are intangible implies that such costs appear in the budget constraints of agents when unions solve their problem but they do not appear in the problem of households.

${ }^{6}$ In the problem below we implicitly define $n_{t}\left(W_{h, t}\right)=\int_{0}^{1}\left(\frac{W_{h, t}}{W_{t}}\right)^{-\nu} d h n_{t}^{d}$.
} 


$$
\max W_{t} n_{t}^{d}-\int_{0}^{1} W_{h, t} n_{h, t} d h \quad \text { s.t. } n_{t}^{d}=\left[\int_{0}^{1} n_{h, t}^{\frac{\nu-1}{\nu}} d h\right]^{\frac{\nu}{\nu-1}}
$$

The first order conditions are:

$$
\begin{aligned}
& n_{h, t}=\left(\frac{W_{h, t}}{W_{t}}\right)^{-\nu} n_{t}^{d} \\
& n_{t}^{d}=\left[\int_{0}^{1} n_{h, t}^{\frac{\nu-1}{\nu}} d h\right]^{\frac{\nu}{\nu-1}}
\end{aligned}
$$

Equation (6) is the demand for labour of type h, already shown in section 2.4. Combining it with (7) one gets the wage index $W_{t}=\left(\int_{0}^{1} W_{h, t}^{1-\nu} d h\right)^{\frac{1}{1-\nu}}$.

\subsection{Intermediate Goods Firms}

Intermediate firm producing good $z$ maximizes profits subject to a Cobb-Douglas production function and to a downward sloping demand function. It also invests, accumulates capital and is subject to a capital adjustment cost and to a productivityaugmented fixed cost of production (Justiniano et al, 2010), chosen so that profits are zero in steady state (Christiano et al, 2005). Finally, it is also subject to a Rotemberg

nominal price adjustment cost $\frac{K}{2}\left(\frac{P_{Z, t}}{P_{Z, t-1}}-1\right)^{2} y_{t}$. Following the assumptions in De Paoli et al (2010), this cost is intangible, in the sense that it is not subtracted to households income but it does enter the price setting decision. The optimization problem is:

$$
\begin{gathered}
\max E_{0} \Sigma_{t=0}^{\infty} \beta^{t} \lambda_{t}^{o}\left[d_{Z, t}-\frac{K}{2}\left(\frac{P_{Z, t}}{P_{Z, t-1}}-1\right)^{2} y_{t}\right] \\
\text { st } D_{Z, t} \leq \frac{P_{Z, t}}{P_{t}} y_{Z, t}-w_{t} n_{Z, t}^{d}-i_{Z, t} \\
y_{Z, t} \leq A_{t}\left(n_{Z, t}^{d}\right)^{\alpha} k_{Z, t-1}^{1-\alpha}-e^{g} f c \\
y_{Z, t}=\left(\frac{P_{Z, t}}{P_{t}}\right)^{-\mu} y_{t} \\
k_{Z, t} \leq(1-\delta) k_{Z, t-1}+\omega\left(i_{Z, t}, k_{Z, t-1}\right) k_{Z, t-1}
\end{gathered}
$$


where the discount factor $\beta^{t} \lambda_{t}^{o}$ reflects the preferences of firms owners, i.e. the Ricardian households, $k_{Z, t}$ is firm owned capital, $A_{t}$ is the technology variable that grows at rate $g$ and is subject to $\mathrm{AR}(1)$ shocks, such that

$$
\log A_{t}=g+\rho \log A_{t-1}+\varepsilon_{t}
$$

where $\varepsilon_{\eta, t}$ is i.i.d. $N\left(0, \sigma_{\eta}^{2}\right)$; and $\omega\left(i_{Z, t}, k_{Z, t-1}\right)=\frac{a_{1}}{1-\frac{1}{X^{K}}}\left(\frac{i_{Z, t}}{k_{Z, t-1}}\right)^{1-\frac{1}{X^{K}}}+a_{2}$ is the capital adjustment cost according to the specification in Jermann (1998) and Uhlig (2007). In this formulation, $X^{K}$ represents the elasticity of the investment to capital ratio with respect to Tobin's $Q$ and the capital adjustment cost is a decreasing function of $X^{K}$.

After aggregating among firms and noticing that all of them choose the same price, the first order conditions for the representative intermediate firm are:

$$
\begin{gathered}
w_{t}=m c_{t} A_{t} \alpha n_{t}^{\alpha-1} k_{t-1}^{1-\alpha} \\
q_{t}=\frac{1}{\left(a_{1}\left(\frac{i_{t}}{k_{t-1}}\right)^{-\frac{1}{X^{K}}}\right)} \\
q_{t}=E_{t}\left\{\beta \frac { \lambda _ { t + 1 } ^ { o } } { \lambda _ { t } ^ { o } } \left(\begin{array}{c}
+q_{t+1}\left[1-\delta+\left(\left(\frac{1}{1-\frac{1}{X^{K}}}-1\right) a_{1}\left(\frac{i_{Z, t}}{k_{t}}\right)^{1-\frac{1}{X^{K}}}+a_{2}\right)\right] \\
m c_{t}=\frac{\mu-1}{\mu}+\frac{K}{\mu}\left(\pi_{t}-1\right) \pi_{t}-\beta E_{t}\left[\frac{\lambda_{t+1}^{o}}{\lambda_{t}^{o}} \frac{K}{\mu}\left(\pi_{t+1}-1\right) \pi_{t+1} \frac{y_{t+1}}{y_{t}}\right] \\
y_{t}=A_{t} n_{t}{ }^{\alpha} k_{t-1}^{1-\alpha}-e^{g} f c \\
k_{t}=(1-\delta) k_{t-1}+\omega\left(i_{t}, k_{t-1}\right) k_{t-1} \\
d_{t}=y_{t}-w_{t} n_{t}-i_{t}
\end{array}\right.\right.
\end{gathered}
$$

For later reference, we define firm earnings, $e_{t}$, as dividends plus retained earnings, which equals re-investment in firm capital, i.e.

$$
e_{t}=d_{t}+i_{t}
$$




\subsection{Final good firms}

Final good firms operate under perfect competition. They aggregate differentiated goods produced by intermediate goods firms and maximize profits subject to a production function of the Dixit-Stiglitz type. The optimization problem is

$$
\max P_{t} y_{t}-\int_{0}^{1} P_{Z, t} y_{Z, t} d z \quad \text { st } y_{t}=\left[\int_{0}^{1} y_{Z, t}^{\frac{\mu-1}{\mu}} d z\right]^{\frac{\mu}{\mu-1}}
$$

The first order conditions read as follows:

$$
\begin{aligned}
& y_{Z, t}=\left(\frac{P_{Z, t}}{P_{t}}\right)^{-\mu} y_{t} \\
& y_{t}=\left[\int_{0}^{1} y_{Z, t}^{\frac{\mu-1}{\mu}} d z\right]^{\frac{\mu}{\mu-1}}
\end{aligned}
$$

Equation (8) is the downward sloping demand function for good z. After combining it with $(9)$, one gets the price index $P_{t}=\left[\int_{0}^{1} P_{Z, t}^{1-\mu}\right]^{\frac{1}{1-\mu}}$.

\subsection{Monetary policy}

The central bank sets the nominal interest rate following a Taylor rule

$$
\log R_{t}^{N}-\left(1-\theta^{R}\right) \log R^{s s}=\theta^{R} \log R_{t-1}^{N}+\left(1-\theta^{R}\right) \theta^{\Pi} \log \pi_{t}
$$

\subsection{Returns and Risk Premia}

The holding period gross returns on equity and consols are, respectively ${ }^{7}$

$$
\begin{gathered}
r_{t, t+1}^{e q}=\frac{V_{t+1}^{e q}+D_{t+1}}{V_{t}^{e q} \pi_{t+1}} \\
r_{t, t+1}^{L}=\frac{\delta^{B} v_{t+1}^{L}+r_{t, t+1}^{R}}{v_{t}^{L}}
\end{gathered}
$$

\footnotetext{
${ }^{7}$ Following Rudebusch and Swanson (2012), we assume that the consol is cum-coupon, i.e. it pays one unit of consumption as coupon to the buyer in the period it is traded. Hence, the holding period return comprises the return obtained from investing that unit of consumption in one period real bonds, $r_{t, t+1}^{R}$. Notice instead that stocks are assumed to be traded ex-dividend, i.e. dividends are paid to the seller in the period in which the transaction takes place. Of course, none of these assumptions has any effect on our results.
} 
The gross long term yield to maturity is given by:

$$
i_{t}^{L}=\frac{\delta^{B} v_{t}^{L}}{v_{t}^{L}-1}
$$

The holding period return and the gross yield to maturity of one period bonds are the same and are equal to:

$$
r_{t, t+1}^{R}=i_{t}^{S}=\frac{1}{v_{t}^{R}}
$$

The equity premium is defined as the difference between the expected holding period return on equity and the short term rate, i.e.

$$
e_{t}^{p}=E_{t}\left[r_{t, t+1}^{e q}\right]-r_{t, t+1}^{R}
$$

Two popular unconditional measures of the term premium are the average yield curve slope and the unconditional expectations of the excess holding period return on long term bonds. The average yield curve slope is given by

$$
Y S=E\left[i_{t}^{L}-i_{t}^{S}\right]
$$

The average excess holding period return on the long term bond is defined as

$$
\text { ehpr }=E\left[r_{t, t+1}^{L}-r_{t, t+1}^{R}\right]
$$

Both the yield curve slope and the excess holding period return may vary over time even when investors are risk-neutral. To study the cyclical behaviour of term premia, we follow Rudebusch and Swanson (2012) and apply a third definition of the term premium. First of all, we define the risk-neutral price of the consol as the price that would prevail if the consol's payoff were discounted using the risk free rate rather than the stochastic discount factor, i.e.

$$
\widetilde{v_{t}^{L}}=1+\delta^{B} \frac{E_{t}\left(\widetilde{v_{t+1}^{L}}\right)}{r_{t, t+1}^{R}}
$$

Then, we compute the risk-neutral yield to maturity as the yield to maturity computed using the risk-neutral price

$$
\widetilde{i_{t}^{L}}=\frac{\delta^{B} \widetilde{v_{t}^{L}}}{\widetilde{v_{t}^{L}}-1}
$$


The term premium can then be defined as the difference between the effective yield to maturity and the risk-neutral yield to maturity, i.e.

$$
T P_{t}=i_{t}^{L}-\tilde{i}_{t}^{L}
$$

The latter measure changes over time only if either the price of risk or the amount of risk change and thus can be used to study the cyclical behaviour of term premia.

\section{Results}

The baseline calibration of the parameters is reported in Table 1 . We follow De Paoli et al (2010) for most parameters. Since we add wage stickiness and LAMP to the model considered by De Paoli et al (2010), we set the elasticity of substitution among labor types, $\nu$, at 6 , and the Rotemberg parameter on wages, $X$, at 77 : the wage mark-up is equal to the price mark-up and wages are as sticky as prices. Following De Graeve et al. (2010), we set the share of RT consumers, $\psi$, at 0.6. This calibration is conservative with respect to Lansing (2014) who sets $\psi=0.9$. Following a standard practice in asset pricing models we calibrate the standard deviation of productivity shocks to match US output growth volatility (Guvenen, 2009 Jermann, 1998, Lansing, 2014) 8

Table 2 reports our results. Its first column reports statistics from the data to be compared to model results. Data appendix 6.2 gives a detailed description of data sources and of computations. All statistics are taken from US data and annualized. Comparison between the baseline specification $(\psi=0.6)$ and the RA model, $(\psi=0)$, confirms that LAMP produces a large increase (decrease) in the unconditional mean equity premium (riskless rate), thereby getting closer to data (the equity premium in the LAMP model is 4.82 against 0.15 in the RA model and 6.76 in the data and the riskless rate in the LAMP model is 1.79 against 4 in the RA model and 1 in the data). Further, LAMP increases unconditional expectations for the yield curve slope and for the excess holding period return on the long term bond and allows to generate significant variation in equity returns, as both ex-post and ex-ante equity return volatility increase substantially compared to the RA model (respectively 23.59 against 4.35 and 5.96 against 0.64 ). Similarly, we obtain that in the LAMP model predicted earnings volatility is 38.20 against 30.80 in the data and 12.76 in the RA model. Moreover, correlations between asset premiums and macro variables, $\rho\left(e_{t}^{p}, \hat{y}_{t}\right)$ and $\rho\left(T P_{t}, \hat{y}_{t}\right)$, are negative and slightly closer to the data than those predicted by

\footnotetext{
${ }^{8}$ We use Dynare to compute a third order approximation of the model, which allow to obtain both unconditional and conditional risk premia.
} 


\begin{tabular}{|c|c|c|}
\hline Parameters & Values & Description \\
\hline$\beta$ & 0.99 & Discount Factor \\
\hline$\alpha$ & 0.64 & Capital Share \\
\hline$\delta$ & 0.025 & Depreciation Rate \\
\hline$\sigma$ & 5 & Coeff. of relative risk aversion \\
\hline$\phi$ & 2.5 & Inverse Frisch elasticity \\
\hline$\psi$ & 0.6 & Share of RT consumers \\
\hline$\chi$ & 0.82 & Habit coefficient \\
\hline$X^{K}$ & 0.3 & Elasticity of investment to capital ratio to Tobin's Q \\
\hline$K$ & 77 & Rotemberg price parameter \\
\hline$X$ & 77 & Rotemberg wage parameter \\
\hline$\nu$ & 6 & Elast. of subst. among labor types \\
\hline$\mu$ & 6 & Elast. of subst. among good types \\
\hline$\theta^{\Pi}$ & 1.5 & Taylor param. on inflation \\
\hline$\theta^{R}$ & 0.75 & Taylor param. on lagged interest rate \\
\hline$a_{1}$ & $\delta^{1 / X^{K}}$ & Param. in capital adj. cost function \\
\hline$a_{2}$ & $\delta-\frac{\delta^{1 / X^{K}}}{1-1 / X^{K}} \delta^{1-1 / X^{K}}$ & Param. in capital adj. cost function \\
\hline$f c$ & 0.2 & Fixed cost \\
\hline$\rho$ & 0.95 & Autocorrelation prod. shock \\
\hline$\pi^{s s}$ & 1 & steady state gross inflation rate \\
\hline$g$ & 0 & Steady state growth rate \\
\hline
\end{tabular}

Table 1: Calibration 
the RA model. Finally, $\rho\left(r_{t-1, t}^{e q}, \widehat{c_{t}}\right)$ performs slightly better in the LAMP model than in the RA model.

To support intuition, consider the second order approximations to the unconditional means for the riskless rate, $r^{R}=\frac{1}{V^{R}}$, for the equity risk premium, $e^{p}$, for the excess holding period return and for the yield spread $!^{9}$

$$
\begin{gathered}
E \ln r_{t, t+1}^{R} \simeq \ln \frac{1}{\beta}+(\sigma-\chi(\sigma-1)) g-\frac{\sigma^{2}}{2} \operatorname{var}_{c^{o}} \\
e^{p}=E\left[r_{t, t+1}^{e q}-r_{t, t+1}^{R}\right]=\frac{1}{\beta} \sigma \operatorname{cov}_{c^{o}, r^{e q}} \\
e h p r=E r_{t, t+1}^{L}-E r_{t, t+1}^{R}=\frac{1}{\beta} \sigma \operatorname{cov}_{c^{o}, r^{L}} \\
Y S \simeq E \ln i_{t}^{L}-E \ln i_{t}^{S}=\frac{1}{2} \sigma^{2}\left[\operatorname{var}_{c^{o}}-\frac{v a r_{c^{o}}^{j}}{j}\right]
\end{gathered}
$$

where $j$ defines maturity of the long-term bond, $\operatorname{var}_{c^{o}}, \operatorname{cov}_{c^{o}, r^{e q}}$ and $\operatorname{cov}_{c^{o}, r^{L}}$, respectively define unconditional expectations of conditional moments computed for variables deviations from their deterministic steady state values, and $\operatorname{var}_{X}^{j} \equiv$ $\operatorname{Var}_{t}\left(X_{t+j}\right)$. Interpretation of (11), (12) and (13) is based on the stochastic discount factor approach. Thus consumption volatility raises precautionary savings. A positive value of $\operatorname{cov}_{c^{o}, r^{e q}}$ is obviously associated to a positive equity premium and, similarly, a positive value of $\operatorname{cov}_{c^{o}, r^{L}}$ is associated to a positive excess holding period return. Finally, in eq. (14) the yield spread is positive if the "long term" variance of the consumption of stockholders is smaller than $\mathrm{j}$ times its conditional variance.

Note that LAMP modifies the effect that volatility of macro variables has on asset returns: 10

\footnotetext{
${ }^{9}$ See the appendix for a derivation of these expressions. Notice that we define $e^{p}=E e_{t}^{p}$.

${ }^{10}$ As above, $\operatorname{var}_{x}$ and $\operatorname{cov}_{x, y}$ are unconditional expectations of conditional moments computed for variables deviations from their deterministic steady state.
} 


$$
\begin{gathered}
\operatorname{var}_{c^{o}}=\left(\frac{\bar{c}}{\overline{c^{o}}}\right)^{2} \operatorname{var}_{c}+\left(\frac{\psi}{1-\psi}\right)^{2}\left(\frac{\bar{d}}{\overline{c^{o}}}\right)^{2} \operatorname{var}_{d}+2\left(\frac{\bar{c}}{\overline{c^{o}}}\right)\left(\frac{\psi}{1-\psi}\right)\left(\frac{\bar{d}}{\overline{c^{o}}}\right) \operatorname{cov}_{c, d} \\
\operatorname{cov}_{c^{o}, r^{e q}}=\frac{\bar{c}}{\overline{c^{o}}} \operatorname{cov}_{c, r^{e q}}+\frac{\psi}{1-\psi} \frac{\bar{d}}{\overline{c^{o}}} \operatorname{cov}_{d, r e q} \\
\operatorname{var}_{c^{o}}^{j}=\left(\frac{c}{c^{o}}\right)^{2} \operatorname{var}_{c}^{j}+\left(\frac{\psi}{1-\psi}\right)^{2}\left(\frac{d}{c^{o}}\right)^{2} \operatorname{var}_{d}^{j}+2\left(\frac{c}{c^{o}}\right)\left(\frac{\psi}{1-\psi}\right)\left(\frac{d}{c^{o}}\right) \operatorname{cov}_{c, d}^{j} \\
\text { where } \frac{\bar{c}}{\overline{c^{o}}}=1-\psi+\frac{1}{1+\frac{\bar{d}}{(1-\psi) \bar{w}}}, \frac{\bar{d}}{\overline{c^{o}}}=\frac{1-\psi}{\frac{\bar{w}}{\bar{d}}(1-\psi)+1},
\end{gathered}
$$

It is easy to see that an increase in $\psi$ unambiguously lowers the impact of consumption volatility because $\frac{\bar{c}}{c^{o}}$ falls, and raises the importance of dividends, whose effect on the marginal utility of Ricardian households' consumption increases in $\psi$.

Our results obtain because the concentration of risky assets in the hands of relatively few households affects the dynamic pattern of their consumption, that is now more volatile and co-varies more strongly with payoffs from risky assets, whose volatility also increases in $\psi$. Price stickiness plays a crucial role in determining these outcomes. In fact Table 2 shows that under full price flexibility the LAMP model is almost indistinguishable from the RA model as all premia vanish. This is in sharp contrast with the previous finding that price stickiness decreases the premium in RA models subject to productivity shocks (De Paoli et al., 2010). Interpretation of our result is straightforward if one looks at IRFs following a productivity shock (Figure 1). Under sticky prices the productivity shock endogenously determines a reduction in the labor income share that is unambiguously stronger under LAMP, because RT consumers cannot smooth consumption when their labor income falls and the shock therefore causes a larger negative consumption gap. The monetary policy stance, identified by $r_{t}^{R}$, becomes gradually expansionary because inflation falls. This, in turn, drives the dynamic pattern of the holding period return and of the yield spread. The favourable wealth effect and the Central Bank policy cause a large increase in Ricardian households consumption that strongly co-varies with equity and bond holding period returns and with the yield spread. The increase of profit margins caused by price stickiness is crucial to obtain both the large wealth redistribution and the strongly expansionary monetary stance. Note that dividends accruing to each Ricardian household are an increasing function of $\psi: d_{t}^{o}=\frac{d_{t}}{1-\psi}$.

Asset pricing models that incorporate LAMP but maintain price flexibility fail to replicate the income redistribution effect of productivity shocks and are therefore forced to assume an additional redistributive shock to match observed assset returns. 
This can be shown more formally if we rearrange the equity premium and the excess holding period return as follows

$$
\begin{gathered}
e^{p}=\frac{1}{\beta}\left(-\operatorname{cov}_{z, r^{e q}}-\operatorname{cov}_{\lambda, r^{e q}}\right) \\
\text { ehpr }=\frac{1}{\beta}\left(-\operatorname{cov}_{z, r^{L}}-\operatorname{cov}_{\lambda, r^{L}}\right)
\end{gathered}
$$

where $z_{t}=\ln \lambda_{t}^{o}-\ln \lambda_{t} ; \lambda_{t}=(1-\psi) \lambda_{t}^{o}+\psi \lambda_{t}^{r t}$. In Danthine et al. (2008) and in De Graeve et al (2010), prices are flexible and the labour contract is such that $\operatorname{cov}_{z, r e q}=0$ and $\operatorname{cov}_{z, r^{L}}=0$ in the absence of exogenous redistributive shocks. ${ }^{11}$ To replicate the empirical risk premium it is therefore necessary to assume that redistributive shocks are negatively correlated with the productivity shock. This shock ensures that full risk sharing is precluded and the consumption marginal utility of workers falls with respect to the consumption marginal utility of firms owners. We can interpret our model as an endogeneization of the redistributive shocks.

Jermann (2008) pinpoints 2 major shortcomings in the results obtaned by asset pricing models based on LAMP and distribuive shocks: i) tendency to generate excessive term premia (an excess holding period return around 10 in contrast with 1.76 in the data), given the properties of distribution risk; ii) reliance on a consumption process for stockholders that is much more volatile than the one found in the data. In particular, while Mankiw and Zeldes (1991) find that the consumption of stockholders is about 1.5 times as volatile as aggregate consumption; in models with limited asset market participation, consumption of stockholders tends to be closer to 10 times as volatile as aggregate consumption.

These criticisms do not apply to our model. As pointed out above, accounting for price stickiness allows to obtain an unconditional expectation that is close to sample mean for $Y S$ and 3.04 for ehpr. Our unconditional expectation for the relative consumption of Ricardian households is 1.93 .

\section{Robustness}

In this section we discuss the robustness of our results to some assumptions we make in the model, such as consumption habits, nominal wage stickiness, and the monetary policy rule.

\footnotetext{
${ }^{11}$ The labor contract assumed by these authors allows perfect risk-sharing between workers and stockholders in the absence of redistributive shocks. This implies that the marginal utilities of the two agents always grow at the same rate and $z_{t}=\ln \lambda_{t}^{o}-\ln \lambda_{t}=0$.
} 


\begin{tabular}{lllll}
\hline & Data & Baseline & $\psi=0$ & $K=0$ \\
\hline$E\left[r_{t, t+1}^{R}\right]$ & 1 & 1.79 & 4 & 3.73 \\
$e^{P}$ & 6.76 & 4.82 & 0.15 & 0.66 \\
$Y S$ & 1.47 & 1.98 & 0.05 & 0.3 \\
$e h p r$ & 1.76 & 3.05 & 0.07 & 0.45 \\
$\rho\left(e_{t}^{P}, \hat{y}_{t}\right)$ & -0.3 & -0.72 & -0.93 & -0.98 \\
$\rho\left(T P_{t}, \hat{y}_{t}\right)$ & -0.38 & -0.87 & -0.94 & -0.96 \\
$\sigma\left(r_{t, t+1}^{e q}\right)$ & 16.72 & 23.59 & 4.35 & 7.94 \\
$\sigma\left[E_{t}\left(r_{t, t+1}^{e q}\right)\right]$ & 8.85 & 5.96 & 0.64 & 1.46 \\
$\rho\left(r_{t-1, t}^{e q}, \hat{c_{t}}\right)$ & -0.17 & -0.06 & -0.03 & 0 \\
$\sigma\left(e_{t, t+1}\right)$ & 30.8 & 38.20 & 12.76 & 11.14 \\
$\frac{\sigma\left(\hat{c}_{t}^{o}\right)}{\sigma\left(\hat{c}_{t}\right)}$ & 1.5 & 1.93 & 1 & 1.19 \\
\hline
\end{tabular}

Table 2: Comparison between data statistics and model. Baseline refers to the model calibrated as in table 1. $\psi=0$ and $K=0$ have the same calibration apart from the share of RT consumers which is set to zero in the first case, and the degree of price stickiness in the second. Appendix 6.2 describes how the statistics from the data are computed. Most data cover the period 1953-2012. The excess holding period return, ehpr, is taken from Rudebusch and Swanson (2012), and the ratio between the volatility of Ricardian households' consumption and the volatility of RT households' consumption, $\frac{\sigma\left(\hat{c_{t}^{o}}\right)}{\sigma\left(\hat{c}_{t}\right)}$ is taken from Mankiw and Zeldes (1991). Hatted variables denote percentage deviations from the steady state for the model and percentage deviations from a Hamilton trend for the data.

\begin{tabular}{lll}
\hline & \multicolumn{3}{c}{$\frac{1}{\beta} \sigma \operatorname{cov}_{c^{o}, r^{e q}}$} \\
\hline & $\frac{1}{\beta} \sigma \frac{\bar{c}}{\bar{c}^{o}} \operatorname{cov}_{c, r e q}$ & $\frac{1}{\beta} \sigma \frac{\psi}{1-\psi} \frac{\bar{d}}{\bar{c}^{o}} \operatorname{cov}_{d, r} e q$ \\
EP Decomposition & 21.5 & 78.5 \\
\hline
\end{tabular}

Table 3: Percentage contributions to the equity premium in the baseline model, table 1 

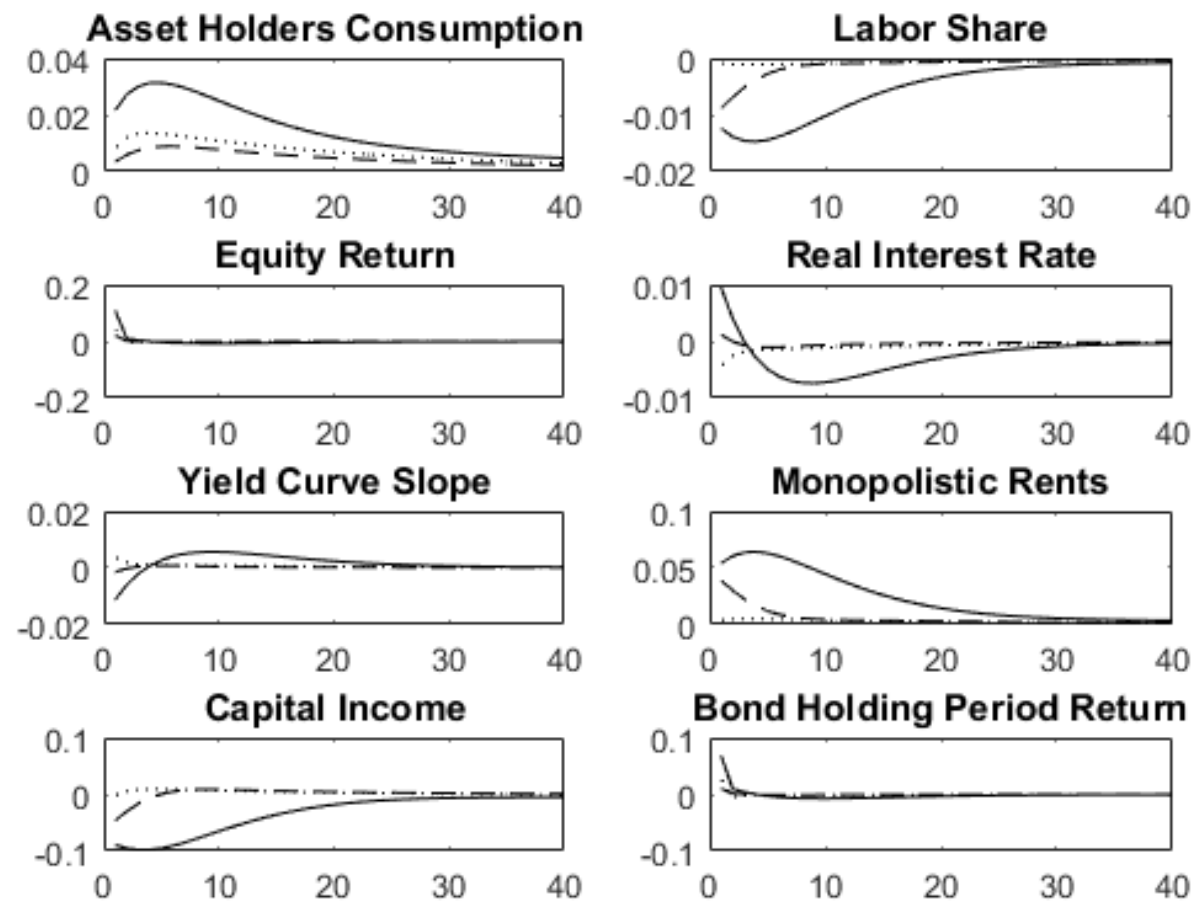

Figure 1: Percentage response to a productivity shock. Full line: sticky price model. Dotted line: flexible price model. Dashed line: representative agent model. 


\subsection{Consumption habits}

Guvenen (2009) argues that LAMP serves as a form of "slow moving external habits". Table 2 shows that under the RA model habits cannot help to replicate $e^{p}$. Under LAMP, as shown by the third column of table 4, all our results concerning financial variables remain unaffected when we set $\chi=0$. As a matter of fact, the habit assumption allows to pin down the relative variability in the consumption of Ricardian households.

In the asset pricing literature based on the RA assumption, the habits-indifferences specification is preferred to the habits-in-ratio characterization because the latter fails to replicate the empirically observed cyclical properties of the risk premium (Campbell and Cochrane, 1999). In our model the combination of habitsin-differences with the LAMP assumption expands the indeterminacy region of the model. To investigate the robustness of our results to the habits-in-differences specification we focus on two cases (Table 4). In the first one, we consider a representative agent model with a large habit coefficient $(\psi=0, \chi=0.82$, fifth column). The riskless rate becomes very large, and the risk premiums collapse. Under this calibration, statistics of dynamic performance, $\sigma\left(r_{t, t+1}^{e q}\right), \sigma\left[E_{t}\left(r_{t, t+1}^{e q}\right)\right]$ and $\sigma\left(e_{t, t+1}\right)$, unambiguously worsen. In the other one, we reintroduce RT consumers $(\psi=0.2)$ and set the habits in difference parameter $\chi$ to 0.5 , the largest value consistent with model determinacy. The presence of LAMP now brings model statistics closer to our baseline results, confirming that LAMP is crucial to replicate risk premiums.

\subsection{Nominal wage rigidity}

The assumption of nominal wage stickiness is consistent with empirical evidence (Barattieri et al. 2014) and maintaining a substantial degree of nominal wage stickiness is crucial to preserve the ability of a standard DSGE model to replicate business cycle facts (Christiano et al. 2005). To assess its role in determining our results we must take into account that under LAMP the combination of flexible wages and sticky prices generates indeterminacy for relatively small values of $\psi$ (Bilbiie, 2008). We therefore adopt a piecemeal approach, gradually lowering both the fraction of RT consumers, $\psi$, and the the nominal wage adjustment cost $X$ (Table 5). Beginning with the case where the fraction of RT households is lowered but wages are sticky ( $\psi=0.2$ and $X=77$ ), we observe that for all statistics the model performance is substantially worse than in our benchmark case. For the same fraction of RT households and almost fully flexible wages, $\psi=0.2$ and $X=5$, we obtain a substantial increase in the risk premia, and good values for several statistics of dynamic per- 


\begin{tabular}{llllll}
\hline & \multicolumn{3}{c}{ Habits in Ratio } & \multicolumn{2}{l}{ Habits in Difference } \\
& Data & Baseline & $\chi=0$ & $\psi=0.2, \chi=0.5$ & $\psi=0, \chi=0.82$ \\
\hline$E\left[r_{t, t+1}^{R}\right]$ & 1 & 1.79 & 1.82 & 2.21 & 3.92 \\
$e^{P}$ & 6.76 & 4.82 & 4.53 & 3.81 & 0.28 \\
$Y S$ & 1.47 & 1.98 & 1.96 & 1.61 & 0.12 \\
$e h p r$ & 1.76 & 3.05 & 3.03 & 2.46 & 0.16 \\
$\rho\left(e_{t}^{P}, \hat{y}_{t}\right)$ & -0.3 & -0.72 & -0.75 & 0.77 & -0.79 \\
$\rho\left(T P_{t}, \hat{y}_{t}\right)$ & -0.38 & -0.87 & -0.89 & -0.95 & -0.88 \\
$\sigma\left(r_{t, t+1}^{e q}\right)$ & 16.72 & 23.59 & 22.01 & 20.28 & 5.25 \\
$\sigma\left[E_{t}\left(r_{t, t+1}^{e q}\right)\right]$ & 8.85 & 5.96 & 5.82 & 4.84 & 0.98 \\
$\rho\left(r_{t-1, t}^{e q}, \hat{c}_{t}\right)$ & -0.17 & -0.06 & 0.06 & -0.01 & -0.11 \\
$\sigma\left(e_{t, t+1}\right)$ & 30.8 & 38.20 & 32.93 & 35.17 & 11.34 \\
$\frac{\sigma\left(\hat{c}_{t}^{o}\right)}{\sigma\left(\hat{c}_{t}\right)}$ & 1.5 & 1.93 & 2.66 & 1.21 & 1 \\
\hline
\end{tabular}

Table 4: Comparison between data statistics and model. Baseline refers to the model calibrated as in table 1. $\chi=0$ to the same model but with habits set to zero, $\psi=0.2, \chi=0.5$ refers to the habit in difference model with share of RT consumers equal to 0.2 and habit parameter equal to 0.5 , and $\psi=0, \chi=0.82$ refers to the representative agent habit in difference model with habit parameter equal to 0.82. Appendix 6.2 describes how the statistics from the data are computed. Most data cover the period 1953-2012. The excess holding period return, ehpr, is taken from Rudebusch and Swanson (2012), and the ratio between the volatility of Ricardian households' consumption and the volatility of RT households' consumption, $\frac{\sigma\left(\hat{c_{t}^{o}}\right)}{\sigma\left(\hat{c_{t}}\right)}$ is taken from Mankiw and Zeldes (1991). Hatted variables denote percentage deviations from the steady state for the model and percentage deviations from a Hamilton trend for the data. 
formance, $\sigma\left(r_{t, t+1}^{e q}\right), \sigma\left[E_{t}\left(r_{t, t+1}^{e q}\right)\right]$ and $\sigma\left(e_{t, t+1}\right)$. However, under this calibration the model largely overshoots the volatility of earnings.

It is interesting to compare our results with those obtained in Uhlig (2007), who assume full price flexibility, no LAMP, a different characterization of the labor market, based on the assumption of real wage rigidity mutuated from Blanchard and Galì (2005), and the presence of both consumption and labor habits. While the Uhlig model contains further differences from our framework ${ }^{12}$ we introduce the latter modifications in our model to get as close as possible to his. The utility function becomes

$$
U\left(c_{t}^{i}, n_{t}^{i}\right)=\frac{1}{1-\sigma}\left(c_{t}^{i}-\chi c_{t-1}\right)^{1-\sigma}-\theta \frac{1}{1+\gamma}\left(n_{t}^{i}-\chi n_{t-1}^{i}\right)^{(1+\gamma)}
$$

where we assume that habits in consumption and labor depend on the same parameter $\chi$; and the following real wage equation

$$
w_{t}=\Omega w_{t-1}^{\mu^{w}}\left(w_{f, t}\right)^{1-\mu^{w}}
$$

replaces equation (5). $\Omega$ is the labor market wedge, $\mu^{w}$ governs the persistence of real wages, and $w_{f, t}$ is the real wage that would obtain under flexible wages and no wedge, i.e.

$$
w_{f, t}=\theta \frac{\left(n_{t}-\chi n_{t-1}\right)^{\gamma}}{\lambda_{t}} .
$$

$\Omega$ is set in such a way to ensure that the steady state labor market wedge in the Uhlig model is the same as in ours ${ }^{13}$ and $\mu^{w}=0.8$, following Uhlig (2007). The baseline version of the Uhlig model generates results which are in general very close to those obtained in our model, with the notable exception of earnings volatility, which is largely underestimated. The Uhlig model, however, is not robust to the standard sticky price assumption. In this case, in fact, the structure of asset returns and the statistics of dynamic performance are at odds with the data. In the last column of Table 6 we present results for a version of the Uhlig model where prices are flexible, the habit coefficient is set at 0.72 and the share of RT consumers is 0.6. ${ }^{14}$ It is easy to see that LAMP does not play any role in this case.

\footnotetext{
${ }^{12}$ For instance, contrary to Uhlig (2007), we have monopolistic competition in both labor and goods markets and our productivity process is different from his. However, even in our version of the Uhlig model it is possible to obtain high risk premia, which suggests that we capture the essential features of it.

${ }^{13}$ In particular, we set $\Omega=e^{1-\mu^{w}} \frac{\mu}{1-\mu}$

${ }^{14} \mathrm{We}$ are forced to impose flexible prices here because with sticky prices and LAMP the model is indeterminate. Even under flexible prices, when $\chi>0.72$ the model is indeterminate for $\psi=0,6$.
} 


\begin{tabular}{lllll}
\hline & Data & Baseline & $\psi=0.2, X=77$ & $\psi=0.2, X=5$ \\
\hline$E\left[r_{t, t+1}^{R}\right]$ & 1 & 1.79 & 3.89 & 3 \\
$e^{P}$ & 6.76 & 4.82 & 0.42 & 3.25 \\
$Y S$ & 1.47 & 1.98 & 0.15 & 0.99 \\
$e h p r$ & 1.76 & 3.05 & 0.23 & 1.93 \\
$\rho\left(e_{t}^{P}, \hat{y}_{t}\right)$ & -0.3 & -0.72 & 0.64 & 0.59 \\
$\rho\left(T P_{t}, \hat{y}_{t}\right)$ & -0.38 & -0.87 & -0.78 & -0.64 \\
$\sigma\left(r_{t, t+1}^{e q}\right)$ & 16.72 & 23.59 & 7.24 & 22.17 \\
$\sigma\left[E_{t}\left(r_{t, t+1}^{e q}\right)\right]$ & 8.85 & 5.96 & 1.49 & 7.79 \\
$\rho\left(r_{t-1, t}^{e q}, \hat{c_{t}}\right)$ & -0.17 & -0.06 & -0.1 & 0.07 \\
$\sigma\left(e_{t, t+1}\right)$ & 30.8 & 38.20 & 19.5 & 79.73 \\
$\frac{\sigma\left(\hat{c}_{t}^{o}\right)}{\sigma(\hat{c t})}$ & 1.5 & 1.93 & 1.14 & 1.56 \\
\hline
\end{tabular}

Table 5: Comparison between data statistics and model. Baseline refers to the model calibrated as in table 1, $\psi=0.2, X=77$ to the same model but with the share of RT consumers set to 0.2 , and $\psi=0.2, X=5$ to the same model but with the share of RT consumers set to 0.2 and the degree of wage stickiness equal to 5 . Appendix 6.2 describes how the statistics from the data are computed. Most data cover the period 1953-2012. The excess holding period return, ehpr, is taken from Rudebusch and Swanson (2012), and the ratio between the volatility of Ricardian households' consumption and the volatility of RT households' consumption, $\frac{\sigma\left(\hat{c}_{t}^{o}\right)}{\sigma\left(\hat{c}_{t}\right)}$ is taken from Mankiw and Zeldes (1991). Hatted variables denote percentage deviations from the steady state for the model and percentage deviations from a Hamilton trend for the data. 


\begin{tabular}{|c|c|c|c|c|c|}
\hline & \multirow{4}{*}{ Data } & \multirow[t]{2}{*}{ Our Model } & \multicolumn{3}{|l|}{ Uhlig(2007) } \\
\hline & & & $K=0$ & $\mathrm{~K}=77$ & $\mathrm{~K}=0$ \\
\hline & & Baseline & $\chi=0.82$ & $\chi=0.82$ & $\chi=0.72$ \\
\hline & & & $\psi=0$ & $\psi=0$ & $\psi=0.6$ \\
\hline$E\left[r_{t, t+1}^{R}\right]$ & 1 & 1.79 & 2.44 & 3.85 & 3.76 \\
\hline$e^{P}$ & 6.76 & 4.82 & 4.04 & 0.48 & 0.62 \\
\hline$Y S$ & 1.47 & 1.98 & 1.58 & 0.18 & 0.29 \\
\hline ehpr & 1.76 & 3.05 & 3.64 & 0.28 & 0.51 \\
\hline$\rho\left(e_{t}^{P}, \hat{y}_{t}\right)$ & -0.3 & -0.72 & -0.69 & -0.7 & -0.95 \\
\hline$\rho\left(T P_{t}, \hat{y}_{t}\right)$ & -0.38 & -0.87 & -0.78 & -0.83 & -0.98 \\
\hline$\sigma\left(r_{t, t+1}^{e q}\right)$ & 16.72 & 23.59 & 21.53 & 7.36 & 7.97 \\
\hline$\sigma\left[E_{t}\left(r_{t, t+1}^{e q}\right)\right]$ & 8.85 & 5.96 & 10.16 & 1.49 & 2.57 \\
\hline$\rho\left(r_{t-1, t}^{e q}, \hat{c_{t}}\right)$ & -0.17 & -0.06 & -0.06 & -0.1 & 0.01 \\
\hline$\sigma\left(e_{t, t+1}\right)$ & 30.8 & 38.20 & 6.93 & 23.56 & 6.4 \\
\hline$\frac{\sigma\left(\hat{c_{t}^{o}}\right)}{\sigma\left(\hat{c_{t}}\right)}$ & 1.5 & 1.93 & 1 & 1 & 1.01 \\
\hline
\end{tabular}

Table 6: Comparison between data statistics and model. Baseline refers to our model calibrated as in table 1 Columns under Uhlig refer to the Uhlig model, calibrated as in table 1, apart from values of $K, \chi$ and $\psi$, which are set to the values reported in the corresponding column. Notice that $\chi$ refers to the habit in ratio coefficient in our model and to the habit in difference coefficient for both consumption and leisure in the Uhlig model. Appendix 6.2 describes how the statistics from the data are computed. Most data cover the period 1953-2012. The excess holding period return, ehpr, is taken from Rudebusch and Swanson (2012), and the ratio between the volatility of Ricardian households' consumption and the volatility of RT households' consumption, $\frac{\sigma\left(\hat{c}_{t}^{o}\right)}{\sigma\left(\hat{c}_{t}\right)}$ is taken from Mankiw and Zeldes (1991). Hatted variables denote percentage deviations from the steady state for the model and percentage deviations from a Hamilton trend for the data. 


\subsection{Monetary policy rule}

To conclude this section we test the robustness of our results to changes in the monetary policy rule. Column 3 and 4 of Table 7 respectively present model statistics when the inflation feedback $\theta^{\Pi}$ is raised from 1.5 to 3 and when the interest rate smoothing coefficient $\theta^{R}$ is reduced from 0.75 to 0 .

As shown in Table 2, price stickiness is a necessary prerequisite for our model to generate substantial risk premiums. Thus our results would vanish if monetary policy could close the marginal cost gap and replicate the flex-price outcome. In fact, by strengthening the inflation feedback we obtain a $30 \%$ reduction in the equity premium, and similar outcomes for $Y S$, ehpr, $\sigma\left(r_{t, t+1}^{e q}\right), \sigma\left[E_{t}\left(r_{t, t+1}^{e q}\right)\right]$ and $\sigma\left(e_{t, t+1}\right)$. A stronger stabilization policy per se reduces consumption risk, inducing Ricardian households to reduce their precautionary savings. This, in turn, explains why the unconditional riskless rate increases. Note that under this policy rule the relative volatility of Ricardian households consumption also falls.

Turning to the effects of removing the interest rate smoothing coefficient, we find that they are almost identical to the consequences of strengthening the inflation feedback, but for quite different reasons.

In fact, as shown by Campbell and Shiller $(1987,1988)$, the persistence of market discount rates is key to understand the "excess volatility" of asset prices relative to distributed dividends. Thus, for any given technological process driving firms ability to generate dividends, the persistence of discount rates raises the volatility of expected payoffs $\frac{V_{t+1}^{e q}+D_{t+1}}{\pi_{t+1}}$ and impacts on risk premiums. In a sticky price model the persistence of the monetary policy rule has a strong impact on the persistence of real rates and this explains why a lower interest rate smoothing coefficient generates the results reported in Table 7 .

\section{Conclusions}

The punchline of the paper is that a fairly standard, workhorse DSGE model useful for business cycle analysis can replicate financial market outcomes if it accounts for LAMP. We introduce LAMP in an otherwise standard DSGE model with real and nominal rigidities. The combination of LAMP and price stickiness is very useful to fit financial data. This result is driven by income redistribution following shocks. The consumption of financial market participants is more volatile than aggregate consumption and more correlated with stock returns. This makes investment in firm shares very risky and provides a justification for the high equity premium found in 


\begin{tabular}{lllll}
\hline & Data & Baseline & $\theta^{\Pi}=3$ & $\theta^{R}=0$ \\
\hline$E\left[r_{t, t+1}^{R}\right]$ & 1 & 1.79 & 2.44 & 2.48 \\
$e^{P}$ & 6.76 & 4.82 & 3.39 & 3.22 \\
$Y S$ & 1.47 & 1.98 & 1.52 & 1.43 \\
$e h p r$ & 1.76 & 3.05 & 2.5 & 2.20 \\
$\rho\left(e_{t}^{P}, \hat{y}_{t}\right)$ & -0.3 & -0.72 & -0.82 & -0.94 \\
$\rho\left(T P_{t}, \hat{y}_{t}\right)$ & -0.38 & -0.87 & -0.84 & -0.93 \\
$\sigma\left(r_{t, t+1}^{e q}\right)$ & 16.72 & 23.59 & 18.53 & 17.8 \\
$\sigma\left[E_{t}\left(r_{t, t+1}^{e q}\right)\right]$ & 8.85 & 5.96 & 4.25 & 3.18 \\
$\rho\left(r_{t-1, t}^{e q}, \hat{c_{t}}\right)$ & -0.17 & -0.06 & -0.09 & -0.04 \\
$\sigma\left(e_{t, t+1}\right)$ & 30.8 & 38.20 & 23.56 & 24.04 \\
$\frac{\sigma\left(\hat{c}_{t}^{o}\right)}{\sigma\left(\hat{c_{t}}\right)}$ & 1.5 & 1.93 & 1.57 & 1.61 \\
\hline
\end{tabular}

Table 7: Comparison between data statistics and model. Baseline refers to our model calibrated as in table 1. Baseline refers to the model calibrated as in table 1, $\theta^{\Pi}=3$ to the same model but with the Taylor parameter on inflation set equal to 3 , and $\theta^{R}=0$ to the same model but without interest rate smoothing. Most data cover the period 1953-2012. The excess holding period return, ehpr, is taken from Rudebusch and Swanson (2012), and the ratio between the volatility of Ricardian households' consumption and the volatility of RT households' consumption, $\frac{\sigma\left(\hat{c}_{t}^{o}\right)}{\sigma\left(\hat{c}_{t}\right)}$ is taken from Mankiw and Zeldes (1991). Hatted variables denote percentage deviations from the steady state for the model and percentage deviations from a Hamilton trend for the data. 
the data. The model is able to account both for the equity premium and for the low correlation of aggregate consumption with equity returns. Further, the strong correlation between dividends and Ricardian households' consumption unambiguously increases precautionary savings and reduces the riskless rate. Our model correctly predicts substantial time variation and countercyclicality of the risk premia.

Our key finding is that stickiness of profit margin, caused by price rigidity, generates idiosyncratic non-insurable risk measured by the correlation between firm profits and equity returns, that is, risk determined by endogenous income redistribution. Empirical DSGE model have been tested for their ability to match business cycle facts by incorporating a wide array of real and nominal shocks. Our results suggest that such shocks may contribute to explain financial variables as well. This is left for future research.

\section{References}

[1] Abel A. B., 1988. "Asset Prices under Habit Formation and Catching up with the Joneses" The American Economic Review, Vol. 80, No. 2, Papers and Proceedings of the Hundred and Second Annual Meeting of the American Economic Association

[2] Barattieri, A., Basu, S., \& Gottschalk, P., 2014. Some evidence on the importance of sticky wages. American Economic Journal: Macroeconomics, 6(1), 70-101.

[3] Bilbiie F. O., 2008. "Limited asset markets participation, monetary policy and (inverted) aggregate demand logic" Journal of Economic Theory, Elsevier, vol. 140(1), pages 162-196, May.

[4] Boldrin M., Christiano L. J. and Fisher J. D. M., 2001. "Habit Persistence, Asset Returns, and the Business Cycle" American Economic Review, American Economic Association, vol. 91(1), pages 149-166, March.

[5] Campbell, J. and Cochrane J., 1999. "By Force of Habit: A ConsumptionBased Explanation of Aggregate Stock Market Behavior" Journal of Political Economy, University of Chicago Press, vol. 107(2), pages 205-251, April.

[6] Campbell, J. Y., 1987. "Stock returns and the term structure," Journal of Financial Economics, Elsevier, vol. 18(2), pages 373-399, June. 
[7] Campbell, J.Y. and Shiller, R.J., 1988. Stock prices, earnings, and expected dividends. The Journal of Finance, 43(3), pp.661-676.

[8] Carroll, C. D., 2000. "Solving consumption models with multiplicative habits" Economics Letters, Elsevier, vol. 68(1), pages 67-77, July.

[9] Christiano L. J., Eichenbaum M. and Evans C. L., 2005. "Nominal Rigidities and the Dynamic Effects of a Shock to Monetary Policy" Journal of Political Economy, University of Chicago Press, vol. 113(1), pages 1-45, February.

[10] Danthine, J.P., Donaldson J.B. and Siconolfi P., 2008. "Distribution risk and equity returns" in R. Mehra (ed.), Handbook of the Equity Risk Premium. North-Holland: Amsterdam, pp. 415-462.

[11] De Graeve, F., Dossche M., Emiris M., Sneessens H. and Wouters R., 2010. "Risk premiums and macroeconomic dynamics in a heterogeneous agent model" Journal of Economic Dynamics and Control, Elsevier, vol. 34(9), pages 1680-1699, September.

[12] Dennis R., 2009. "Consumption Habits in a New Keynesian Business Cycle Model" Journal of Money, Credit and Banking, Blackwell Publishing, vol. 41(5), pages 1015-1030, 08.

[13] De Paoli B., Scott A. and Weeken O., 2010. "Asset pricing implications of a New Keynesian model" Journal of Economic Dynamics and Control, Elsevier, vol. 34(10), pages 2056-2073, October.

[14] Dixit A. K and Stiglitz J. E, 1977. "Monopolistic Competition and Optimum Product Diversity" American Economic Review, American Economic Association, vol. 67(3), pages 297-308, June.

[15] Furlanetto, F. and Seneca, M., 2012. "Rule-of-Thumb Consumers, Productivity, and Hours" The Scandinavian Journal of Economics, 114: 658-679. doi: $10.1111 / j .1467-9442.2012 .01699 . x$

[16] Galí J., López-Salido J. D. and Vallés J., 2004. "Rule-of-Thumb Consumers and the Design of Interest Rate Rules Journal of Money" Credit and Banking Vol. 36, No. 4 (Aug., 2004), pp. 739-763 
[17] Galí J., López-Salido J.D. and Vallés J., 2007. "Understanding the Effects of Government Spending on Consumption" Journal of the European Economic Association, MIT Press, vol. 5(1), pages 227-270, 03.

[18] Guvenen F., 2009. "A Parsimonious Macroeconomic Model for Asset Pricing" Econometrica, Econometric Society, vol. 777(6), pages 1711-1750, November.

[19] Justiniano A., Primiceri G.E. and Tambalotti A., 2010. "Investment shocks and business cycles" Journal of Monetary Economics, Elsevier, vol. 57(2), pages 132-145, March.

[20] Jermann, Urban J., 1998. "Asset pricing in production economies," Journal of Monetary Economics, Elsevier, vol. 41(2), pages 257-275, April.

[21] Jermann, Urban J., 2008. "Discussion: Distribution Risk and Equity Returns," in Mehra, R.v (ed.) Handbook of the Equity Risk Premium, Elsevier, Pages $463-466$

[22] James D. Hamilton, 2017. "Why You Should Never Use the Hodrick-Prescott Filter," NBER Working Papers 23429, National Bureau of Economic Research, Inc.

[23] Lansing K., 2014. "Asset Pricing with Concentrated Ownership of Capital and Distribution Shocks" http://www.frbsf.org/publications/economics/papers/2011/wp11-07bk.pdf, Forthcoming in American Economic Journal - Macroeconomics

[24] Leeper E., Walker T.B. and Yang S-C. S., 2009. "Government Investment and Fiscal Stimulus in the Short and Long Runs" NBER Working Papers 15153.

[25] Lettau M., 2003. "Inspecting The Mechanism: Closed-Form Solutions For Asset Prices In Real Business Cycle Models" Economic Journal, Royal Economic Society, vol. 113(489), pages 550-575, 07.

[26] Mankiw N.G. and Zeldes S.P., 1991. "The consumption of stockholders and nonstockholders" Journal of Financial Economics, Elsevier, vol. 29(1), pages 97-112

[27] Mehra R. and Prescott E.C., 1985. "The equity premium: A puzzle" Journal of Monetary Economics, Elsevier, vol. 15(2), pages 145-161, March. 
[28] Motta G and Tirelli P, 2013a. "Optimal Simple Monetary and Fiscal Rules under Limited Asset Market Participation" Journal of Money, Credit and Banking, Blackwell Publishing, vol. 44(7), pages 1351-1374, October.

[29] Motta G and Tirelli P, 2013b. "Limited Asset Market Participation, Income Inequality and Macroeconomic Volatility" Working Papers 261, University of Milano-Bicocca, Department of Economics, revised Dec 2013.

[30] Polkovnichenko V., 2004. "Limited stock market participation and the equity premium" Finance Research Letters 1 (March), 24-34.

[31] Rotemberg J.J. (1982). "Sticky prices in the United States" Journal of Political Economy, 90: 1187-1211.

[32] Rudebusch G.D. and Swanson E.T., 2012. "The Bond Premium in a DSGE Model with Long-Run Real and Nominal Risks" American Economic Journal: Macroeconomics, American Economic Association, vol. 4(1), pages 105-43, January.

[33] Shiller R., 2015. "ONLINE DATA ROBERT SHILLER" http://www.econ.yale.edu/ shiller/data.htm

[34] Smets F. and Wouters R., 2007. "Shocks and Frictions in US Business Cycles: A Bayesian DSGE Approach" American Economic Review, American Economic Association, vol. 97(3), pages 586-606, June.

[35] Uhlig H., 2007. "Explaining Asset Prices with External Habits and Wage Rigidities in a DSGE Model" American Economic Review, American Economic Association, vol. 97(2), pages 239-243, May.

[36] Weil P., 1992. "Hand-to-mouth consumers and asset prices" European Economic Review, Elsevier, vol. 36(2-3), pages 575-583, April. 


\section{Appendix}

\subsection{Second order approximations to asset returns}

In this appendix, we derive the asset prising expressions reported in the main text. Taking logs of the marginal utility of consumption of Ricardian agents yields: 15

$$
\widehat{\lambda}_{t}^{o}=-\sigma \widehat{c_{t}^{o}}+\chi(\sigma-1) \widehat{c_{t-1}}
$$

As a consequence, the stochastic discount factor can be expressed as:

$$
\widehat{s d f_{t}^{o}}=\widehat{\lambda}_{t}^{o}-\widehat{\lambda}_{t-1}^{o}=-\sigma \Delta \widehat{c_{t}^{o}}+\chi(\sigma-1) \Delta \widehat{c_{t-1}}
$$

where for any generic variable $h, \Delta h_{t}=h_{t}-h_{t-1}$.

De Paoli et al (2010) show that the real rate can be expressed as: $\widehat{r}_{t}^{R}=$ $-E_{t} \widehat{s d f_{t+1}^{o}}-\frac{1}{2} \operatorname{Var}_{t} \widehat{s d f_{t+1}^{o}}$. The conditional expectation of the stochastic discount factor is simply:

$$
E_{t} \widehat{s d f_{t+1}^{o}}=-\sigma E_{t} \Delta \widehat{c_{t+1}^{o}}+\chi(\sigma-1) \Delta \widehat{c_{t}}
$$

The conditional variance is instead given by:

$$
\operatorname{Var}_{t} \widehat{s d f_{t+1}^{o}}=\sigma^{2} \operatorname{Var}_{t} \Delta \widehat{c_{t+1}^{o}}
$$

So the real interest rate at time $t$ is:

$$
\widehat{r}_{t, t+1}^{R}=\sigma E_{t} \Delta \widehat{c_{t+1}^{o}}-\chi(\sigma-1) \Delta \widehat{c_{t}}-\frac{1}{2} \sigma^{2} \operatorname{Var}_{t} \Delta \widehat{c_{t+1}^{o}}
$$

Taking the unconditional expectations of the latter expression and using the law of iterated expectations, we get the average (stochastic steady state) riskless rate:

$$
E \widehat{r}_{t, t+1}^{R}=(\sigma-\chi(\sigma-1)) g-\frac{1}{2} \sigma^{2} E \operatorname{Var}_{t} \Delta \widehat{c_{t+1}^{o}}
$$

In the main text we define the conditional (co)variances of any variables $h, j$ evaluated at the stochastic steady state $\operatorname{ECov}_{t}\left(h_{t+1}, j_{t+1}\right)\left(\operatorname{EVar}_{t}\left(h_{t+1}\right)\right)$ as $\operatorname{cov}_{h, j}\left(\operatorname{var}_{h}\right)$. Notice that up to a second order conditional second moments are constant, hence $\operatorname{Var}_{t}\left(h_{t+1}\right)=\operatorname{var}_{h} \forall t$ and $\operatorname{Cov}_{t}\left(h_{t+1}, j_{t+1}\right)=\operatorname{cov}_{h, j} \forall t$. Rearranging terms we get:

$$
E \ln r_{t, t+1}^{R}=\ln \frac{1}{\beta}+(\sigma-\chi(\sigma-1)) g-\frac{\sigma^{2}}{2} \operatorname{var}_{c^{o}}
$$

\footnotetext{
${ }^{15}$ From now on, log-deviations from the deterministic steady state are expressed with a hat.
} 
which is the expression reported in the main text.

The second order approximations of the equity premium and of the excess holding period return can be expressed respectively as

$e_{t}^{p}=E_{t} r_{t, t+1}^{e q}-r_{t, t+1}^{R}=\frac{1}{\beta}\left(E_{t}\left[\widehat{r}_{t, t+1}^{e q}\right]-\widehat{r}_{t, t+1}^{R}+\frac{1}{2} \operatorname{Var}_{t}\left(\widehat{r}_{t, t+1}^{e q}\right)\right)=-\frac{1}{\beta} \operatorname{Cov}_{t}\left(\widehat{s d f}_{t+1}^{o}, \widehat{r}_{t, t+1}^{e q}\right)$

and as

$\operatorname{ehpr}_{t}=E_{t} r_{t, t+1}^{L}-r_{t, t+1}^{R}=\frac{1}{\beta}\left(E_{t}\left[\widehat{r}_{t, t+1}^{L}\right]-\widehat{r}_{t, t+1}^{R}+\frac{1}{2} \operatorname{Var}_{t}\left(\widehat{r}_{t, t+1}^{L}\right)\right)=-\frac{1}{\beta} \operatorname{Cov}_{t}\left(\widehat{s d f}_{t+1}^{o}, \widehat{r}_{t, t+1}^{L}\right)$

Since the covariance between equity returns and the stochastic discount factor is $-\sigma \operatorname{Cov}_{t}\left(\widehat{c}_{t+1}^{o}, \widehat{r}_{t, t+1}^{e q}\right)$ and $-\sigma \operatorname{Cov}_{t}\left(\widehat{c}_{t+1}^{o}, \widehat{r}_{t, t+1}^{L}\right)$, respectively, we get:

$$
e_{t}^{p}=\frac{1}{\beta} \sigma \operatorname{Cov}_{t}\left(\widehat{c}_{t+1}^{o}, \widehat{r}_{t, t+1}^{e q}\right)
$$

and

$$
\operatorname{ehpr}_{t}=\frac{1}{\beta} \sigma \operatorname{Cov}_{t}\left(\widehat{c}_{t+1}^{o}, \widehat{r}_{t, t+1}^{L}\right)
$$

Again, making the same assumption we made while deriving the riskless rate and taking unconditional expectations, we can rewrite the above as in the main text:

$$
E e_{t}^{p}=E r_{t, t+1}^{e q}-E r_{t, t+1}^{R}=\frac{1}{\beta} \sigma \operatorname{cov}_{c^{o}, r e q}
$$

and

$$
e h p r=E e h p r_{t}=E r_{t, t+1}^{L}-E r_{t, t+1}^{R}=\frac{1}{\beta} \sigma \operatorname{cov}_{c^{o}, r^{L}}
$$

To obtain our second order approximation of the yield spread, we start from the expression reported in De Paoli et al (2010), i.e. $Y S \simeq E \ln i_{t}^{L}-E \ln i_{t}^{S}=$ $\frac{1}{2}\left[\operatorname{Var}_{t}\left(\widehat{s d f_{t+1}^{o}}\right)-\frac{\operatorname{Var}_{t}\left(\widehat{s d f_{t+j}^{o}}\right)}{j}\right]$, which can be rewritten as

$$
Y S \simeq E \ln i_{t}^{L}-E \ln i_{t}^{S}=\frac{1}{2} \sigma^{2}\left[\operatorname{Var}_{t}\left(\widehat{c_{t+1}^{o}}\right)-\frac{\operatorname{Var}_{t}\left(\widehat{c_{t+j}^{o}}\right)}{j}\right]
$$

or, using the definition reported above and $\operatorname{EVar}_{t}\left(h_{t+j}\right)=\operatorname{var}_{h}^{j}$, as

$$
Y S \simeq E \ln i_{t}^{L}-E \ln i_{t}^{S}=\frac{1}{2} \sigma^{2}\left[\operatorname{var}_{c^{o}}-\frac{\operatorname{var}_{c^{o}}^{j}}{j}\right]
$$


In order to re-express everything in terms of aggregate variables, consider the budget constraint of the representative Ricardian household (eq. ??) and aggregate consumption

$$
c_{t}=(1-\psi) c_{t}^{o}+\psi c_{t}^{r t}=w_{t} n_{t}+d_{t}
$$

Then, take the difference between Ricardian agents' consumption and aggregate consumption, namely

$$
c_{t}^{o}-c_{t}=\frac{d_{t}}{1-\psi}-d_{t}
$$

Rearranging the equation, one gets

$$
c_{t}^{o}=c_{t}+\frac{\psi}{1-\psi} d_{t}
$$

Finally, we take the loglinear approximation of the above expression, which delivers

$$
\widehat{c}_{t}^{o}=\frac{\bar{c}}{\overline{c^{o}}} \widehat{c}_{t}+\frac{\psi}{1-\psi} \frac{\bar{d}}{\overline{c^{o}}} \widehat{d}_{t}
$$

From the latter expression, one can get:

$$
\begin{gathered}
\operatorname{var}_{c^{o}}=\left(\frac{\bar{c}}{\overline{c^{o}}}\right)^{2} \operatorname{var}_{c}+\left(\frac{\psi}{1-\psi}\right)^{2}\left(\frac{\bar{d}}{\overline{c^{o}}}\right)^{2} \operatorname{var}_{d}+2\left(\frac{\bar{c}}{\overline{c^{o}}}\right)\left(\frac{\psi}{1-\psi}\right)\left(\frac{\bar{d}}{\overline{c^{o}}}\right) \operatorname{cov}_{c, d} \\
E e_{t}^{p}=r^{e q}-r^{R}=\frac{1}{\beta}\left(\sigma \operatorname{cov}_{c^{o}, r^{e q}}\right)=\frac{\sigma}{\beta}\left(\frac{\bar{c}}{\overline{c^{o}}} \operatorname{cov}_{c, r^{e q}}+\frac{\psi}{1-\psi} \frac{\bar{d}}{\overline{c^{o}}} \operatorname{cov}_{d, r^{e q}}\right) \\
e h p r=r^{L}-r^{R}=\frac{1}{\beta}\left(\sigma \operatorname{cov}_{c^{o}, r^{L}}\right)=\frac{\sigma}{\beta}\left(\frac{\bar{c}}{\overline{c^{o}}} \operatorname{cov}_{c, r^{L}}+\frac{\psi}{1-\psi} \frac{\bar{d}}{\overline{c^{o}}} \operatorname{cov}_{d, r^{L}}\right)
\end{gathered}
$$

and

$Y S \simeq E \ln i_{t}^{L}-E \ln i_{t}^{S}=\frac{1}{2} \sigma^{2}\left[\begin{array}{c}\left(\frac{\bar{c}}{\bar{c}^{o}}\right)^{2} \operatorname{var}_{c}+\left(\frac{\psi}{1-\psi}\right)^{2}\left(\frac{\bar{d}}{\bar{c}^{o}}\right)^{2} \operatorname{var}_{d}+2\left(\frac{\bar{c}}{\bar{c}^{o}}\right)\left(\frac{\psi}{1-\psi}\right)\left(\frac{\bar{d}}{\bar{c}^{o}}\right) \operatorname{cov}_{c, d} \\ -\frac{\left(\frac{\bar{c}}{c^{o}}\right)^{2} \operatorname{var}_{c}^{j}+\left(\frac{\psi}{1-\psi}\right)^{2}\left(\frac{\bar{d}}{c^{o}}\right)^{2} \operatorname{var}_{d}^{j}+2\left(\frac{\bar{c}}{c^{o}}\right)\left(\frac{\psi}{1-\psi}\right)\left(\frac{\bar{d}}{c^{o}}\right) \operatorname{cov}_{c, d}^{j}}{j}\end{array}\right]$

To obtain the decomposition of the equity premium and of the excess holding period return in equation (??) and in equation define optimizers relative marginal utility $\left(z_{t}=\frac{\lambda_{t}^{o}}{\lambda_{t}}\right)$ and take $\operatorname{logs}\left(z_{t}=\lambda_{t}^{o}-\lambda_{t}\right)$. The equity premium can be expressed as $e_{t}^{p}=\frac{1}{\beta}\left(-\operatorname{Cov}_{t}\left(\widehat{z}_{t+1}, \widehat{r}_{t, t+1}^{e q}\right)-\operatorname{Cov}_{t}\left(\widehat{\lambda}_{t+1}, \widehat{r}_{t, t+1}^{e q}\right)\right)$, which unconditionally becomes:

$$
E e_{t}^{p}=\frac{1}{\beta}\left(-\operatorname{cov}_{z, r^{e q}}-\operatorname{cov}_{\lambda, r^{e q}}\right)
$$


The excess holding period return can be expressed as ehpr $\frac{1}{\beta}\left(-\operatorname{Cov}_{t}\left(\widehat{z}_{t+1}, \widehat{r}_{t, t+1}^{L}\right)-\operatorname{Cov}_{t}\left(\widehat{\lambda}_{t+1}, \widehat{r}_{t, t+1}^{L}\right)\right)$, which unconditionally becomes

$$
e h p r=\frac{1}{\beta}\left(-\operatorname{cov}_{z, r^{L}}-\operatorname{cov}_{\lambda, r^{L}}\right)
$$

The latter expressions are the ones reported in the main text.

\subsection{Data}

Data concerning equity statistics, earnings and consumption were taken from Robert Shiller's website (2015). The volatility of real equity returns was computed as the standard deviation of the raw data. The trend in the logs of real earnings and consumption was removed using a Hamilton (2017) filter with one lag and a two years horizon, as suggested for annual frequency data. The standard deviation of earnings and the correlation of consumption with the return on equity was computed using the resulting detrended data.

Data on interest rates were taken from FRED. In particular, the riskless rate is the real return on three months Treasury Bills, while the yield slope is the difference between the ten years Treasury constant maturity rate and the riskless rate. They have monthly frequency and were deflated using the CPI index. Statistics on equity returns, consumption, earnings, and interest rates were computed for the period 1953-2012.

For what concerns data on expected equity returns and expected inflation, we used the Livingston survey data. Livingston data are collected bi-annually, in June and December, and ask questions about S\&P500 index value for a period of six months and one year. We computed our statistics using the one year median expectations. As the survey asks about expected equity prices in one year, we had to reconstruct the implied expected equity return. As expectations about dividends are not reported, we adopted the shortcut of assigning to each period the average dividend yield computed from Shiller's data. The short term interest rate to be subtracted from the expected return on equity to obtain the expected equity premium was the annualized three months Treasury return obtained from FRED for the period June 1953-June 1991, given that over that period the T-bill rate was not reported in the survey data, and the T-bill interest rate expectations for the end of the month in which the survey is taken thereafter. To compute the expected real equity return, we deflated the nominal expected return using the one year inflation expectations.

The term premium is the one computed using the Kim and Wright method and was obtained from FRED. The dataset begins in 1990 and so we used the data 
beginning in that year. The dataset has daily frequency: to keep consistency with the computations for equity, we transformed it to semiannual using the average of business days. To obtain the real term premium, we added the six months expected inflation rate and subtracted the ten years expected inflation rate obtained from the Livingston survey. While we should have added the three months expected inflation rate rather than the six months one, only the latter is available in the survey. However, inflation adjustment does not influence the results substantially.

To compute the correlation of the expected equity premium and term premium with output, we obtained quarterly real GDP from FRED and transformed it to semiannual computing the average over quarters 1 and 2 and quarters 3 and 4 respectively. We detrended it using a Hamilton (2017) filter with 2 lags and a 4 periods horizon on its log. The correlation with expected equity premium was computed using the resulting detrended output over the six months period before the date of the survey. 